\title{
La Educación Imaginativa y la enseñanza de la historia
}

\author{
María de la Luz Matte ${ }^{1}$ \\ Recibido: 1 de junio de 2018 - Aprobado: 31 de agosto de 2018
}

\begin{abstract}
Resumen
Este artículo analiza las propuestas de la Educación Imaginativa y sus potencialidades para la enseñanza de la historia. En la primera parte se reseñan los postulados teóricos de la Educación Imaginativa, centrando el análisis en las propuestas de uno de sus principales impulsores, el filósofo de la educación Kieran Egan. En la segunda parte se estudia la manera en que este enfoque puede ser utilizado en la enseñanza de la historia, proporcionando, además, algunos ejemplos concretos. Según Egan, la enseñanza de la historia ha quedado reducida a los currículos, dejando de lado los aspectos vinculados con las emociones y la imaginación, lo que ha impactado el desarrollo integral de los estudiantes como miembros de la sociedad. A partir de la experiencia y la revisión bibliográfica, proponemos una aproximación a esta teoría, explicando sus fundamentos, sus principios y cómo esta puede ser una valiosa herramienta para la enseñanza de la historia.
\end{abstract}

Palabras clave: Educación Imaginativa, entendimientos, herramientas cognitivas, enseñanza de la historia.

\section{Imaginative Education and the teaching of history}

\begin{abstract}
This article analyzes proposals of Imaginative Education and its potential for teaching history. The first part presents the theoretical postulates of the Imaginative Education focusing on the proposals of one of its main promoters, the education philosopher Kieran Egan. In the second part, it studies the way in which this approach can be used in teaching history, also providing some examples. According to Egan, the curricula has reduced the teaching of history to the transmission of knowledge without relating it to emotions and imagination, impacting students' integral development as members of society. From the experience and the bibliographic review we propose an approach
\end{abstract}

1 Chilena. Magíster en Docencia para la Educación Superior, Universidad Nacional Andrés Bello, Chile. Académica de la Escuela de Educación, Universidad Finis Terrae, Chile. E-mail: mmatte@uft.cl 
to this theory, explaining its foundations, its principles and how this can be a valuable tool for the teaching of history.

Keywords: Imaginative education, understandings, cognitive tools, history teaching.

\section{A Educação Imaginativa e o ensino da história \\ Resumo}

Este artigo analisa as propostas da Educação Imaginativa e suas potencialidades para o ensino da história. Na primeira parte são resumidos os postulados teóricos da Educação Imaginativa centrando a análise nas propostas de um dos seus principais impulsores, o filósofo da educação Kieran Egan. Na segunda parte estuda-se a maneira em que esta perspectiva pode ser utilizada no ensino da história proporcionando, ao mesmo tempo, alguns exemplos concretos. Segundo Egan, o ensino da história tem ficado reduzido nos currículos à transmissão de conhecimentos ignorando os aspectos vinculados com as emoções e a imaginação, o que tem impactado o desenvolvimento integral dos estudantes como membros da sociedade. A partir da experiência e a revisão bibliográfica propomos uma aproximação a esta teoria, explicando seus fundamentos, seus princípios e como esta pode ser una valiosa ferramenta para o ensino da história.

Palavras-chave: Educação Imaginativa, entendimentos, ferramentas cognitivas, ensino da história.

\section{Introducción}

La Educación Imaginativa ha sido desarrollada en la Universidad Simon Fraser, Canadá, por el doctor en Educación, Kieran Egan y el Centro de Investigación en Educación Imaginativa, asociado a la Facultad de Educación de esa universidad. Este enfoque propone una particular teoría que postula cómo el ser humano va comprendiendo el mundo en la medida que se desarrolla, mediante herramientas cognitivas; pero su foco, y de ahí viene su denominación, está en involucrar al alumno en el aprendizaje, apelando a sus emociones y a su imaginación para mantenerlo motivado. Las herramientas cognitivas son el medio para lograrlo.

Desde la perspectiva de la Educación Imaginativa, según los postulados de su autor Kieran Egan, se considera que la enseñanza de la historia ha quedado reducida a los currículos, particularmente en los dirigidos a educación de la primera infancia y básica, afectando con esto su proceso de formación y desarrollo no solo intelectual, sino que integral como miembros de una sociedad.

Egan plantea una serie de argumentos, desde su particular concepción de la educación, para una aproximación diferente a la historia. Su teoría 
explica cómo se va dando el desarrollo cognitivo en el niño en la medida en que logra una mayor sofisticación en el uso del lenguaje, lo que le permite ir complejizando su forma de comprender el mundo, en formas que él llama entendimientos, a los cuales se asocian herramientas cognitivas. En este artículo ofrecemos una introducción a la Educación Imaginativa para favorecer el aprendizaje de la historia, logrando una mejor comprensión de la teoría y didáctica de la misma.

\section{La Educación Imaginativa y la enseñanza de la historia}

La enseñanza de la historia es fundamental para que el sujeto comprenda la sociedad o cultura en la que se desarrolla, por lo tanto, la percepción y comprensión del entorno que tenga el niño va a depender en mayor o menor medida de cómo esta se enseña. Desde ahí que nos hemos planteado la inquietud respecto a cómo puede la Educación Imaginativa contribuir al aprendizaje de la historia, incorporando a la didáctica de las historia las herramientas cognitivas que plantea la Educación Imaginativa.

Para responder esta pregunta hay que comprender de qué estamos hablando. La Educación Imaginativa, muy poco difundida aún en Chile, es una forma de comprender el aprendizaje y, por lo tanto, la enseñanza, basada en involucrar afectivamente al estudiante en este proceso, apelando a su imaginación. Esta teoría asume la definición de imaginación como "la capacidad de pensar en las cosas, como posibles de ser o suceder; es un acto intencional de la mente y es lo que nos permite inventar, innovar, crear". Todos estos conceptos están directamente relacionados con lo que la sociedad del siglo XXI demanda a la educación, es decir, formar personas reflexivas, críticas, creativas, innovadores, que no solo saben aprender, sino que están en constante aprendizaje. Estos postulados están en directa relación con el desarrollo de habilidades que plantea el currículo nacional, no solo para la asignatura de historia, sino que para aquellas transversales como la resolución de problemas. Tan solo estos argumentos sirven para validar a la Educación Imaginativa como una herramienta importante para la enseñanza, no solo de la historia, sino que de cualquier disciplina y en cualquier contexto.

El autor de esta teoría es el destacado filósofo de la educación Kieran Egan², quien la ha elaborado producto de una larga experiencia educando

2 Kieran Egan nació en 1942 en Clonmel, Irlanda, aunque fue criado y educado en Inglaterra. Se graduó de la Universidad de Londres con una licenciatura en Historia en 1966. Posteriormente trabajó como investigador en el Institute for Comparative Studies en Kingston upon Thames. Luego se trasladó a Estados Unidos donde se graduó de Doctor en Educación en la Universidad de Cornell en 1972. Es uno de los más importantes filósofos educacionales contemporáneos, autor de la teoría sobre la Educación Imaginativa, fundador y director 
y formando profesores en Inglaterra, Estados Unidos y Canadá. En conjunto con un grupo de académicos de la Universidad Simon Fraser de Vancouver, Canadá, fundaron el Centro de Investigación en Educación Imaginativa (IERG, por sus siglas en inglés). Su teoría se basa principalmente en el papel que juega la imaginación en el aprendizaje y cómo los profesores la utilizan para motivar a sus estudiantes. De acuerdo a sus postulados, se considera que la motivación es el factor fundamental y condicionante para que el alumno se involucre en el proceso de aprendizaje. Las herramientas que desarrolla esta teoría son aplicables en cualquier contexto y tienen como principal objetivo contribuir a que los estudiantes, sin importar la edad, desarrollen una comprensión reflexiva del mundo.

Su trabajo se inicia mucho antes de que tuviéramos los conocimientos que aporta la neurociencia a la educación en relación a la manera como aprende el ser humano. Sin embargo, hoy día se valida también desde esta ciencia, principalmente en la concepción del aprendizaje y la importancia que tiene la imaginación como elemento clave para lograr la motivación para que este sea efectivo. Egan, en su libro Mentes Educadas (2018), nos dice:

"En educación hay sofisticados campos de estudios psicológicos y filosóficos. Lo primero se ha centrado en aprendizaje, desarrollo psicológico, motivación, etcétera. Lo segundo en la naturaleza, la estructura y la secuencia lógica del conocimiento, en el análisis de los conceptos educacionales clave, en los elementos constituyentes del ideal de una persona educada, etcétera. Han habido muy pocos estudios sobre la imaginación, por razones que discutiremos. Y han habido aún menos estudios que se focalicen en los tipos de entendimiento que resultan de estos tres trabajando juntos, como los hay, según nuestra experiencia. En parte esta carencia se debe a las sofisticadas herramientas de investigación derivadas de la psicología y de la filosofía analítica. Dados los objetivos con los que fueron diseñadas estas herramientas, no es extraño que no hayan apoyado a aquellos que hayan querido realizarlos para enfocarse en temas que son transversales y proyectan los campos en los cuales operan más

del Equipo de Investigación de Educación Imaginativa de la Universidad de Simon Fraser, Vancouver, Canadá. Actualmente, es profesor emérito de la misma universidad y forma parte de la National Academy of Education de Estados Unidos como asociado extranjero y participa de la Canada Research Chair en el área de educación. Ha sido ganador del Premio Grameweyer que concede la Universidad de Lousville, Estados Unidos, y el año 2016 obtuvo el Cmolik Prize por su contribución a la mejorar la educación pública en el distrito de British Columbia, Canadá. Ha publicado numerosos libros, tales como, Teaching as storytelling (1986), The Educated Mind (1997), editado en español por la Universidad Finis Terrae (2018), Getting it wrong from the beginning (2002), An imaginative approach to teaching (2005) y Learning in depth (2010). 
efectivamente. Aun así, la investigación que se desarrolla acá se apoya o usufructúa en una importante medida en ambos estudios psicológicos y filosóficos sobre la educación; no se hubiera podido realizar sin el trabajo en esas áreas tradicionales de investigación en educación. Lo que yo he querido explorar es, entonces, el carácter cambiante de los productos de la imaginación, de la acumulación de conocimiento y del desarrollo psicológico trabajando juntos en el proceso educativo. Esto es, yo he tratado de alguna manera de caracterizar la educación en una forma diferente, una forma que es, a mi juicio, más comprensible y de manera práctica más valiosa que los muchos discursos educacionales. He tratado de caracterizar la educación en términos de una nueva categoría mediante la consideración de la imaginación, la acumulación de conocimientos y el desarrollo psicológico trabajando juntos. Esta categoría es lo que yo llamo tipos de entendimiento. Yo he identificado y descrito cinco tipos de entendimientos distintos que caracterizan mejor el proceso de desarrollo educacional que los derivados de corrientes educacionales psicológicas y filosóficas Los he llamado entendimientos: somático, mítico, romántico, filosófico e irónico" (Egan, 2018: 48).

En síntesis, el planteamiento de la Educación Imaginativa, consiste en que el ser humano, a lo largo de su desarrollo, adquiere formas de comprender el mundo, que llama "entendimientos", cada vez más complejas, y asocia a cada entendimiento una serie de herramientas cognitivas que potencian o favorecen el aprendizaje en los estudiantes.

El trabajo realizado por el Grupo de Investigación en Educación Imaginativa de la Universidad Simon Fraser, Canadá, ha sido reconocido internacionalmente por proponer programas prácticos, innovadores, exitosos y, lo que es también importante, que no requieren de grandes recursos educativos ni económicos, sino que se basan y requieren la decisión de un profesor que comprenda esta aproximación a la educación y se atreva a implementarla. Se ha puerto en práctica, de hecho, en países con culturas tan disímiles como Japón, Italia Canadá, Estados Unidos, Inglaterra, México y Chile, entre otros, logrando buenos resultados de aprendizaje, igualmente con estudiantes que traen un muy buen capital cultural de base y con aquellos que vienen de contextos deprivados socioculturalmente. ¿Por qué? Porque su foco está en mostrarnos cómo la emoción, la imaginación y la motivación son claves para que el alumno se involucre en el aprendizaje de manera eficaz y eficiente. El IERG ha desarrollado para cada tipo de entendimiento herramientas cognitivas, técnicas y métodos simples y versátiles para que sean puestas en práctica por profesores en la enseñanza de todas las asignaturas de cualquier curriculum. En este caso abordaremos cómo se puede implementar para la enseñanza de la Historia. 
Nosotros los seres humanos tenemos, al igual que los animales, un cerebro que nos da la capacidad de desarrollar acciones físicas y sociales. En este proceso de interacción vamos acumulando una cantidad de material simbólico externo conformado por la alfabetización y la cultura. En la medida en que el cerebro va reconociendo y aprendiendo de nuestra herencia cultural, va adquiriendo herramientas que le permiten ir desarrollando cada vez acciones intelectuales más complejas. Si bien estamos condicionados genéticamente para hablar, no aprendemos a hablar si estamos aislados del resto de los seres humanos, tampoco aprendemos a leer ni a escribir, no logramos realizar procesos de abstracción de generalización de conceptos e indudablemente no aprendemos a comprender la historia en soledad. Estas potenciales capacidades humanas solo se actualizan mediante el aprendizaje y aprendiendo a utilizar algunos elementos fundamentales o piezas almacenadas en nuestro bagaje cultural. La cultura, plantea Egan, utilizando una analogía muy simple, "programa el cerebro"; naturalmente esto es demasiado simplístico, pero nos permite una aproximación al rol que tiene la cultura en la enseñanza de la historia en la Educación Imaginativa. ${ }^{3}$

¿Cuál es el sustento que tiene su teoría hoy en día? Durante mucho tiempo, todos los que fuimos formados en pedagogía -al menos durante la segunda mitad del siglo XX-, sustentábamos nuestro quehacer en determinadas teorías del aprendizaje, lo que impactaba desde el diseño curricular a las prácticas en el aula y a la evaluación. Estos enfoques, como bien lo dice su nombre, eran mayoritariamente teorías, porque no se contaba con los avances científicos y tecnológicos que permitieran evidenciar cómo aprende el ser humano o qué ocurre en un cerebro en aprendizaje. En este sentido, los aportes de las neurociencias han confirmado algunas de estas teorías, así como también han derribado ciertos mitos que existían al respecto. Parte de estas concepciones tenían que ver con la creencia de que los seres humanos estamos determinados biológicamente para nuestro desarrollo, y la influencia que se le reconocía al contexto era menor. Si analizamos la teoría de Piaget (Egan, 2018: 40), cuyo aporte a la educación es innegable, vemos que esta centra el aprendizaje en el alumno, y afirma que el ser humano pasa por estadios de desarrollo cognitivo vinculados a su edad, o como dice Ken Robinson (2017), a su fecha de fabricación, los niños entre los cero y los dos años tienen un patrón homogéneo de desarrollo y procesan la información de acuerdo a esas características y así sucesivamente hasta llegar al estadio de las operaciones formales. Las neurociencias, con la absoluta evidencia de la neuroplasticidad cerebral, han resignificado el rol de la educación y, por ende, de los educadores y del ambiente o contexto de aprendizaje, por sobre

3 Más antecedentes sobre el IERG pueden ser consultados en: $\mathrm{http}$ ///ierg.ca//HT/foundationsiht/, revisado el 20-V-2018. 
la determinación biológica. Este contexto no está limitado a la escuela, se refiere a la familia, a la sociedad y a la cultura en la que se desarrolla un sujeto. Desde esta dimensión, la importancia de cómo se ha construido esa sociedad y esa cultura, y la comprensión de parte del educador para contextualizar los diseños curriculares y las prácticas pedagógicas resultan fundamentales.

La evidencia de la plasticidad neuronal viene a confirmar, por otra parte, la teoría del aprendizaje de Lev Vygotsky (Baquero, 2004: 31) y la modificabilidad cognitiva que desarrolló Reuven Feuerstein (Vedovelli, 2014). Relevan la importancia del educador que es capaz de generar un ambiente propicio para que cada sujeto construya su propio aprendizaje; pero todavía más, valida el rol de las emociones en el proceso de aprendizaje, condiciona el aprendizaje a la motivación, la que si bien es y debe ser intrínseca del alumno, depende del contexto de aprendizaje que diseñe el profesor, de las estrategias que utiliza, entre otros factores. Egan, en su teoría, destaca el rol de las emociones en el aprendizaje, invita a los profesores a utilizar la imaginación, innata en todo ser humano, para que sus alumnos se involucren en este, cuestiona fuertemente las limitaciones de muchos currículos que consideran que el niño no puede abstraer y que no puede aprender nada que no esté vinculado con una realidad concreta, $y$, desde esa perspectiva, pasan años aprendiendo sobre su barrio, su comunidad, porque hablarles de la historia occidental sería imposible, ya que no serían capaces de comprenderlo. No consideramos, o no lo hacemos lo suficiente, la maravillosa capacidad que tiene el ser humano de imaginar, cómo esta imaginación está presente desde el nacimiento, cómo es esta misma a la que apelan los cuentos infantiles, ¿no representan una época muy distinta, un hábitat muy distinto, no les hablamos y ellos ciertamente valoran superhéroes, duendes, hadas, castillos, etcétera? ¿No será que estamos limitando a nuestros niños desde nuestra propia perspectiva adulta y creencias sobre el desarrollo del ser humano, fuertemente arraigadas en nuestra cultura occidental? ¿Por qué habríamos de limitarlos, si hoy sabemos que cada sujeto tiene una infinita capacidad de generar en sus cerebros redes neuronales, que en definitiva son redes conceptuales y que esa capacidad no se puede predeterminar, ni mucho menos limitar? Por estas razones, la teoría de la Educación Imaginativa se sustenta primariamente en el análisis que hace su creador, desde la filosofía a la educación, desde la teoría de Lev Vygotsky y desde las neurociencias. Esta teoría surge entonces desde la investigación y la reflexión; pero también desde la experiencia misma de Kieran Egan y es enriquecida por el equipo de investigadores del IERG. ${ }^{4}$

4 Al ser consultado Kiegan Egan sobre el origen de sus planteamientos y relación con la educación tradicional, señaló "siempre tuve mis cuestionamientos al sistema y cómo se estaba enseñando, pero cuando realmente empecé a plasmar esta teoría fue cuando fui padre y comencé a observar a mis hijos, su interacción con el mundo, con las personas y sobre todo a sus preguntas" (Entrevista personal, Kieran Egan, I-2015). 
La comprensión de los tipos de entendimiento y las herramientas cognitivas asociadas a cada una de ellos es fundamental para entender el aporte de la Educación Imaginativa a la enseñanza de la historia. Para abordarlos ahondaremos brevemente en cómo se desarrolla lo que Egan llama "una nueva idea". Se basa en las teorías de la recapitulación y en Vygotsky, argumentando que las teorías de la recapitulación permiten establecer "una conexión causal precisa entre el desarrollo cultural del pasado y el desarrollo educativo del presente" (Egan, 2018: 52). De esta manera, nos proporcionan herramientas con mecanismos para el particular carácter del desarrollo cultural que contribuyan a conformar el proceso de la educación. Vygotsky toma esta teoría pero desde otra perspectiva; según él, comprendemos el mundo mediante el uso de instrumentos intelectuales mediadores, los que influyen directamente en el tipo de conocimiento que tenemos. Por lo tanto, para comprender el desarrollo intelectual del ser humano no hay que centrarse en el conocimiento construido, sino que en los instrumentos utilizados para construirlo y éstos se encuentran disponibles en la sociedad en la que se desarrolla una persona.

Desde el desarrollo del lenguaje oral, que es en sí mismo un instrumento intelectual, el sujeto va interiorizando estos instrumentos, pasando por procesos interpsíquicos hasta llegar a los intrapsíquicos, lográndose los más elevados en las interacciones con otras personas, en un contexto social con determinadas funciones sociales; por lo tanto, el desarrollo del lenguaje resulta fundamental para lograr cada vez una mejor y más sofisticada (desde el punto de vista intelectual) comprensión del mundo. "Mediante esta interiorización de maneras históricamente determinadas y culturalmente organizadas de actuar sobre la información, la naturaleza social de las personas acaba siendo también su naturaleza psicológica" (Luria, 1979: 45, en Egan, 2018: 81). Por lo tanto, el proceso de desarrollo intelectual se debe reconocer en el grado de dominio que tienen los individuos de instrumentos y sistemas simbólicos como el lenguaje (Vygotsky, 1978). El desarrollo de los instrumentos intelectuales conduce a maneras de comprensión cualitativamente distintas: "El sistema simbólico reestructura todo el proceso psicológico" (Egan, 2018: 35). Así, el conjunto de sistemas simbólicos que interioricemos a partir de las interacciones con unos grupos culturales concretos y con unas comunidades determinadas, influirá decisivamente en la comprensión del mundo que podremos construir.

\section{¿Cómo llevamos esto al aprendizaje de la historia?}

Uno de los grandes cuestionamientos que hace Egan a los currículos, y en particular a la enseñanza de la historia para los niños más pequeños, es que son limitantes porque obedecen a una concepción de las capacidades 
ser humano que inhibe su imaginación, su afán de explorar y conocer y, por lo tanto, su desarrollo. Afirma que "los niños pequeños disponen de las herramientas conceptuales que necesitan para aprender los aspectos más profundos de nuestro pasado, como la lucha por la libertad y contra la violencia arbitraria por la seguridad y contra el miedo, etcétera. No aprenden estos conceptos pues ya disponen de ellos cuando llegan a la escuela. Los utilizan para aprender aspectos del mundo y de la experiencia" (Egan, 2018: 95). Su preocupación radica en "Los primeros años de enseñanza incluyen muy poca historia y, la que hay, se suele ocupar de hechos locales o regionales que han influido en el entorno del niño de alguna manera significativa. La historia ha sido prácticamente eliminada del currículo elemental en respuesta a la doctrina progresista de que debemos empezar a explorar el mundo partiendo de lo que el niño ya sabe y experimenta, y de que debemos ampliar gradualmente su comprensión a partir de su entorno cotidiano. También se debe al progresismo la eliminación del currículo de aquellos contenidos que no permiten una participación activa de los niños, porque la enseñanza elemental se orienta básicamente a "aprender a hacer" (Dewey, 1966: 184) y la experiencia práctica de sucesos históricos es claramente imposible. Además, Dewey sostenía que "el verdadero punto de partida de la historia siempre es alguna situación actual con sus problemas" (Dewey, 1966: 214). La disminución o la exclusión de la historia también han sido apoyadas por la investigación piagetiana, que demostró que ciertos conceptos cruciales para la comprensión histórica eran "operaciones formales" que no se "desarrollan" hasta la adolescencia (Elkind, 1976; Hallam, 1969). Además, la explicación de Piaget de que el pensamiento de los niños pequeños se encuentra en el nivel "preoperacional" o en el de las "operaciones concretas", ha hecho suponer que no pueden abordar el material histórico con provecho. El efecto acumulado de estas influencias es un currículo que hace que los niños pequeños desconozcan prácticamente la historia, porque se supone, en primer lugar, que no pueden entenderla y, en segundo lugar, que su atención y su actividad se deben centrar en su experiencia cotidiana y en su entorno local para extenderse a partir de ahí.

Algunos conceptos "formales" esenciales para la comprensión histórica, como la causalidad, no se "desarrollan" durante la adolescencia a partir de la nada. Y aunque los niños pequeños no puedan captar el concepto de la causalidad histórica, sí que captan claramente el principio causal que impregna relatos como "Hansel y Gretel", "La Cenicienta" o "Peter Rabbit", el popular conejo creado por Beatrix Potter. Además, para que los adolescentes desarrollen unos conceptos sofisticados de la causalidad histórica se debe estimular y desarrollar unos conceptos causales previos. La "causalidad narrativa" de "Peter Rabbit" es un evidente precursor lógico de la causalidad histórica de Tucídides. En lugar de eliminar la historia 
del currículo, podríamos introducir contenidos históricos estructurados en función de los conceptos que los niños pequeños sí entenderían. Estos conceptos no solo se harían accesibles mediante una extensión ordenada de las actividades prácticas cotidianas del niño, sino también, y quizá con un atractivo mayor, mediante el empleo de la estructuración binaria que demuestra ser tan común en el pensamiento de los niños.

Por ejemplo, podríamos introducir en el primer curso una historia narrada del mundo, estructurada en función de la oposición entre la libertad y la opresión, el conocimiento y la ignorancia o la seguridad y el miedo. Estas oposiciones son claramente significativas para los niños pequeños porque las vemos en sus cuentos favoritos, en sus propias narraciones fantásticas y en las explicaciones que dan de la comprensión de sus propias experiencias (Paley, 1981, 1984, 1990).

Egan, en síntesis, plantea que en la enseñanza de la historia, desde su percepción, hoy día está reducida a las experiencias previas, conocimientos previos y visión concreta del mundo, y que la utilización de todos estos elementos, más las herramientas cognitivas que en su teoría asocia a los distintos tipos de entendimientos que van desarrollando nuestros alumnos, permitirían una mayor profundización desde el inicio de la escolaridad de la enseñanza de la historia y el desarrollo de habilidades asociadas a ella; pero también aquellas transversales, junto con asumir que la historia en sí misma es espectacular y atractiva para los niños. En ella encontramos dramatismo, personajes vívidos atractivos con cualidades heroicas; si le damos forma a su relato, simplificando la realidad, utilizando conceptos que forman parte de su vida cotidiana y que no le son ajenos, como la libertad y opresión, la justicia y la injusticia, se logra que ellos comprendan que estos conceptos son parte del mundo en el que viven. Son estas las herramientas cognitivas, las que llevan de la teoría a la práctica a la Educación Imaginativa y las que sugiere incorporar en la enseñanza de la historia, en realidad en todo el currículo, pero él, seguramente por su formación, ha tenido una especial preocupación por la historia.

\section{¿Qué son estas herramientas cognitivas?}

Las herramientas cognitivas, como hemos mencionado, están asociadas a los tipos de entendimiento que el ser humano va desarrollando en la medida que interactúa en un contexto, pero que también es educado. Estas se pueden utilizar, de alguna manera, como estrategias metodológicas que aportan a la didáctica de cualquier disciplina. En este caso son, además, un medio para involucrar afectiva y efectivamente a los estudiantes y nos permiten comprender nuestra historia y su significado. 
Las herramientas cognitivas que utilizamos actúan como lentes que influencian directamente en la interpretación que le damos al mundo que nos rodea. La riqueza o la complejidad de nuestro conjunto de herramientas cognitivas determinan una mayor y mejor comprensión que tengamos de nuestro contexto; estas herramientas "median" la forma en la que vemos y comprendemos las cosas y el mundo.

La teoría de la Educación Imaginativa plantea que las personas, a lo largo de su desarrollo, van sumando tipos de entendimientos en la medida que sofistican el uso del lenguaje, pasando desde una etapa inicial prelingüística, en la que los seres humanos nacemos y somos somáticos, es decir, nuestra primera aproximación al mundo que nos rodea y, por lo tanto, a su comprensión y construcción del conocimiento proviene de lo que podemos percibir con nuestros sentidos. Luego, en la medida que el sujeto desarrolla y aprende el lenguaje oral, tiene otra forma de conectarse y comprender el mundo, hasta llegar a un tipo de entendimiento en el que hace un uso reflexivo del lenguaje, el que el autor llama "irónico". Esto, a diferencia de otras teorías y como lamentablemente sí se hace en educación muchas veces, no significa que debamos abandonar lo somático y sus experiencias, considerando esta como una etapa superada. La teoría plantea que a lo largo del desarrollo y de la vida de todos ser humano, se van sumando herramientas cognitivas que surgen desde el sistema de símbolos que nos va aportando la sofisticación de lenguaje, partiendo desde la oralidad hasta aquellas que se van complejizando en gran medida por la adquisición del lenguaje, al uso teórico del lenguaje hasta llegar a la capacidad de reflexión sobre este. Cada una de estas adquisiciones significan un tipo de entendimiento, con sus herramientas que se suman a las que ya tenemos.

La siguiente tabla ilustra cada entendimiento y las herramientas cognitivas asociadas a cada uno. Si se analiza en detalle se puede observar cómo se va sobreponiendo un entendimiento sobre el otro, aportando nuevas herramientas, sin dejar nunca de lado del entendimiento previo: 


\section{Tabla 1}

Tipos de entendimiento y herramientas cognitivas

\begin{tabular}{|c|c|c|c|c|}
\hline $\begin{array}{l}\text { Somático } \\
\text { (Pre- } \\
\text { lingüística) }\end{array}$ & $\begin{array}{l}\text { Mítico } \\
\text { (Lenguaje } \\
\text { verbal) }\end{array}$ & $\begin{array}{l}\text { Romántico } \\
\text { (Lenguaje } \\
\text { Escrito) }\end{array}$ & $\begin{array}{l}\text { Filosófico } \\
\text { (Uso teórico } \\
\text { del lenguaje) }\end{array}$ & $\begin{array}{l}\text { Irónico } \\
\text { (Uso reflexivo } \\
\text { del lenguaje) }\end{array}$ \\
\hline \multirow[t]{5}{*}{$\begin{array}{l}\text {-Sentidos del } \\
\text { cuerpo } \\
\text {-Ritmo y } \\
\text { musicalidad } \\
\text {-Humor } \\
\text {-Gestos y } \\
\text { comunicación } \\
\text {-Respuestas } \\
\text { emocionales y } \\
\text { apegos }\end{array}$} & $\begin{array}{l}\text {-Historias } \\
\text {-Opuestos } \\
\text { binarios } \\
\text {-Metáfora } \\
\text { rima, métrica y } \\
\text { patrón } \\
\text {-Chistes y } \\
\text { humor } \\
\text {-Formación de } \\
\text { imágenes } \\
\text {-Sentido del } \\
\text { misterio } \\
\text {-Juegos y } \\
\text { drama }\end{array}$ & $\begin{array}{l}\text {-Sentido de } \\
\text { realidad } \\
\text {-Extremos y } \\
\text { límites de la } \\
\text { realidad } \\
\text {-Rebeldía e } \\
\text { idealismo } \\
\text {-Cambio } \\
\text { contextual } \\
\text {-Asombro } \\
\text {-Colección y } \\
\text { pasatiempos } \\
\text {-Humanización } \\
\text { y } \\
\text { personificación } \\
\text { del } \\
\text { conocimiento } \\
\text {-Asociación } \\
\text { con héroes }\end{array}$ & $\begin{array}{l}\text {-Manejo de la } \\
\text { generalidad } \\
\text {-Procesos } \\
\text {-La seducción } \\
\text { de la certeza } \\
\text {-Flexibilidad de } \\
\text { la teoría } \\
\text {-Esquemas } \\
\text { generales y } \\
\text { anomalías } \\
\text {-Búsqueda de } \\
\text { la autoridad y } \\
\text { de la verdad }\end{array}$ & $\begin{array}{l}\text {-Límites de la } \\
\text { teoría } \\
\text {-Reflexividad e } \\
\text { identidad } \\
\text {-Particularidad } \\
\text {-Postura } \\
\text { socrática }\end{array}$ \\
\hline & Somático & Mítico & Romántico & Filosófico \\
\hline & & Somático & Mítico & Romántico \\
\hline & & & Somático & Mítico \\
\hline & & & & Somático \\
\hline
\end{tabular}

Fuente: http://ierg.ca/about-us/a-brief-guide-to-imaginative-education/, revisado el 10-IV-2018.

El desafío para la educación, y en este caso para la enseñanza de la historia, es cómo estimular, usar y desarrollar estas herramientas para motivar a los alumnos hacia su aprendizaje. El aporte de la teoría de Vygotsky en este punto consiste en su explicación del desarrollo intelectual del ser humano y cómo nuestra imaginación influencia la captación de conocimiento.

Otro aspecto fundamental para aplicar la Educación Imaginativa en la enseñanza en la historia proviene de los estudios sobre las culturas orales y cómo estas con su forma mítica de pensamiento, utilizaban y utilizan el pasado como fuente no solo para generar una nueva forma de conocimiento 
sobre éste, sino que también para comprender su rol en el mundo actual. Esto no quiere decir que Egan compare a los niños de hoy con las tradicionales culturas orales; pero sí que analizamos las herramientas cognitivas propias de estas culturas como las imágenes mentales, la narración, los opuestos binarios, la formación de patrones; podemos asegurar que si las utilizamos en la enseñanza de la historia es posible involucrar afectivamente a los estudiantes en el aprendizaje de la historia. Pero, ¿Cómo lo hacemos? ¿Estimulando su imaginación o apelando a su bagaje cultural o capacidad de abstracción? Y más importante aún, en este apartado es esencial decir a qué nivel de enseñanza estamos apuntando. ¿Esto sirve para básica y media, pre-escolar? ¿Entre qué rangos de edad? Y si sirve para todos, entonces hay que dejar claro que, independiente de la edad, las condiciones son las mismas.

Tomando como referencia el trabajo realizado por el IERG, dividiremos las herramientas, de las que hemos estado hablando y se ilustran en la tabla anterior, en dos grandes categorías: las primeras son aquellas utilizadas por las culturas orales y que aún hoy día son usadas por cualquier ser humano que aprende a hablar, muy especialmente los niños pequeños, en la medida en que se van alfabetizando y comienzan el aprender información histórica y desarrollar un pensamiento histórico. Estas están asociadas a los primeros tres tipos de entendimiento: somático, místico y romántico. En segundo lugar, aquellas que se adquieren en la medida en que se va logrando un mayor desarrollo intelectual, asociadas al entendimiento filosófico e irónico. Si el profesor logra comprender cuáles son las herramientas que subyacen al desarrollo de los seres humanos y las relaciona con los procesos históricos y cómo estos se observan en el desarrollo de un individuo, encontrará formas de no solo acercar los alumnos a la historia con un aprendizaje memorístico, sino que a su real comprensión.

Analizando algunas de estas herramientas, podemos ejemplificar cómo utilizarlas y cuán prácticas y aplicables a la didáctica de la historia y geografía pueden ser:

Opuestos binarios abstractos: herramienta asociada a la comprensión mítica, es quizás una de las herramientas más básicas y poderosas que utiliza la Educación Imaginativa. Apenas desarrollamos el lenguaje oral, pareciera ser necesario, para tener una primera comprensión del mundo, establecer categorías, no de cualquier tipo, sino que categorías con base en opuestos como poco/mucho, grande/chico, o los que encontramos en los cuentos infantiles como La Cenicienta (buenos/malos, ricos/pobres). Los niños desarrollan estas categorías binarias abstractas; por eso, usarlas en la enseñanza de la Historia no solo facilita su comprensión, sino que los motiva y los lleva a la reflexión. A continuación, un ejemplo también desarrollado en el IERG aplicado a las ciencias sociales. Para explorar cómo la naturaleza y los humanos definen o 
construyen las características de su entorno se puede contraponer una serie de características del campo y la ciudad. ¿Cuáles son las cualidades y valores que distinguen al campo y a la ciudad? ¿Por qué, particularmente la gente de la ciudad, busca ir al campo de vacaciones? ¿Qué tipo de cosas, elementos se encuentran en una zona rural versus una urbana? ¿Por qué cuando la gente vive en entornos construidos por urbanos, se dice que la vida va una velocidad o tiene un ritmo más acelerado que en entornos naturales?

Imágenes mentales: no son cuadros ni ilustraciones, son representaciones en forma de imágenes mentales que uno puede evocar con solo una conversación. Son afectivas y efectivas porque hay un componente emocional vinculado a ellos. No están relacionados con grandes pasiones, es simplemente involucrar la emoción de los estudiantes de una manera casual. Por ejemplo, si estamos en una clase de geografía y estamos hablando de los océanos y sus características, se puede recurrir a las imágenes que tienen los alumnos del mar, ya sea porque hayan tenido vivencias o información y desde ahí hacer el análisis para llegar a conceptos más complejos. La no utilización de ellos es lamentable porque las imágenes mentales son poderosos agentes comunicativos del significado e ignorarlos es dejar de lado una herramienta muy importante para el proceso de enseñanza. Indiscutiblemente, el crear o elaborar estas imágenes en torno a palabras o conceptos es de una enorme importancia emocional, pues influencia la motivación de un alumno sobre estos. En una sociedad saturada de imágenes visuales es importante generar los espacios para que los alumnos construyan sus imágenes mentales; muchas veces la imagen que tenemos relacionada con una palabra tiene una potencia imaginativa y emocional más que el concepto en sí mismo y eso es lo que debemos llevar a la enseñanza.

Juegos, drama, actuación: se asocian generalmente con la distracción, el entretenimiento, el ocio. Cada uno de ellos puede, sin embargo, jugar un rol muy importante en el aprendizaje. Representan las formas más básicas de la interacción humana, las personas se involucran fácilmente en ellos y generalmente lo hacen con agrado. Complementariamente, implican una serie de habilidades, incluyendo la capacidad de representar eventos por medio de la narrativa y pueden expandir la comprensión de un conocimiento. El juego contribuye al desarrollo de una cantidad de funciones simbólicas. Quizás algunos de los ejemplos más útiles e ilustrativos sea el juego fantasioso de los niños, en el que asumen roles, usan palabras imaginarias, trasmitiendo sin parar mientras lo hacen, ajustando las reglas a su juego y en definitiva pasándolo muy bien. Un valor esencial del juego es que permite a la mente reflejar el mundo: si somos el malo, así actuamos. Desarrolla el pensamiento en un metanivel y nos permite pensar libres de las formalidades, comportamiento y propósitos diarios bajo los cuales funcionamos en nuestra vida cotidiana. También contribuye a la autorregulación. Si se asume un rol, se aprende a comportarse de acuerdo con este. En este juego se desarrolla la 
imaginación el pensamiento, en contraste con los juegos electrónicos, que son comparados por muchos con la comida rápida, ya que su efecto en el cerebro de los niños sería similar al de esta comida en las arterias. En una clase imaginativa se espera ver mucho juego; el tipo de juego que se vea: inventivos, competitivos, de tableros, puzles, etcétera, dependerá del tema que se esté enseñando.

Veamos un ejemplo asociado a la enseñanza de la historia: las profesoras pueden crear escenarios imaginarios en los que los estudiantes deben tomar decisiones, evaluar las consecuencias de sus decisiones y en lo posible afrontar estas consecuencias. Los estudiantes pueden crear sus propios escenarios, representando posibles resultados basados en sus decisiones. Por ejemplo, se les puede pedir que representen el conflicto surgido de la interacción entre los exploradores europeos y los pueblos originarios y traten de resolver el conflicto de la repartición de tierras.

Asociaciones con héroes: todos los seres humanos pasamos por la etapa de "idolatrar" a personajes que pueden ser reales, pero también de la historia o la literatura. Si estamos enseñando el antiguo Egipto, por ejemplo, la tendencia natural es resaltar los legados de esta civilización, sus pirámides, los jeroglíficos, su religión, su estructura de gobierno. Pero detrás de todo esto estaban los seres humanos que vivieron en esa época y desarrollaron su cultura: ¿Cómo eran? ¿Cómo sería viajar, observar o participar en la construcción de esos monumentos o poder ver esos mercados, con las caravanas llegando por el río Nilo? ¡Poder ver eso, no solo imaginarlo, sería una aventura maravillosa, digna de un súper héroe! Podemos ciertamente usarlo en una clase de historia, involucrando las emociones y los conocimientos de los estudiantes vinculando estas características a cualidades heroicas.

Esquemas o conceptualizaciones generales y sus anomalías: esta herramienta nos permite percibir y construir ideas abstractas sobre la sociedad, la naturaleza, la historia y la psicología humana, para luego descubrir que cada generalización tiene en sí misma una anomalía, la que nos permite llegar a reflexiones e ideas más complejas. Si el profesor enseña teorías, esquemas generales, ideologías y luego a través de preguntas lleva a sus alumnos a cuestionarse su generalización, logra un pensamiento no solo reflexivo, sino que argumentativo, en el que logran valorar estas generalizaciones; pero comprender que no siempre se pueden aplicar, que depende de la circunstancia y el contexto. Un ejemplo aplicable en historia: el concepto es el colonialismo; si estamos en un mundo donde se propicia la igualdad de derechos, ¿cuál o cuáles fueron los motivos para que los colonizadores trataran a sus conquistados? ¿Cómo lo hicieron? ¿Este fenómeno fue igual en todo el mundo? ¿Tuvo algo que ver con los pueblos originarios o con los conquistadores? 
A continuación, un ejemplo de cómo llevar esta teoría y, en particular, cómo aplicar las herramientas cognitivas al diseño curricular de aula:

Una herramienta que es siempre muy eficaz en la enseñanza es el "cuento, las historias asociadas a la temática". Este ejemplo esta tomado del libro Fantasía e Imaginación: su poder en la enseñanza (Egan, 2008):

1. Descubrir qué es lo importante:

¿Qué es lo más importante del tema?

¿Por qué puede interesar a los estudiantes?

¿Qué tiene de interesante desde el punto de vista afectivo?

2. Encontrar pares opuestos:

¿Qué pares opuestos con suficiente fuerza captan mejor la importancia del tema?

3. Organización del contenido en forma de cuento:

¿Qué contenido incluye de modo más espectacular los pares opuestos, con el fin de introducir el tema?

¿Qué contenido estructura mejor el tema para su desarrollo en forma de cuento?

4. Conclusión.

¿Cuál es la mejor forma de resolver el dramático conflicto inherente a los pares opuestos?

¿Qué grado de mediación entre estos pares opuestos conviene buscar?

5. Evaluación:

¿Cómo podemos saber si se ha entendido el tema, si se ha captado su importancia y se ha aprendido el contenido?

Ejemplos hay muchos y seguramente cualquier profesor que quiera explorar esta teoría, sus tipos de entendimientos y, particularmente, las herramientas cognitivas asociadas a cada uno de ellos, puede aventurarse y utilizarlas en sus prácticas en el aula.

\section{Conclusión}

Egan tiene una visión crítica de algunas teorías del aprendizaje, las que, desde su percepción, lo limitan y que, en particular, no consideran un as- 
pecto que hoy sabemos que es relevante, que es involucrar afectivamente a los estudiantes en el proceso, de manera que se sientan motivados hacia un aprendizaje no solo significativo sino que profundo La Educación Imaginativa toma el aspecto emocional como factor condicionante para este tipo de aprendizaje, sin dejar de lado otros postulados de cómo enseñar, en particular las didácticas de cada disciplina, ofreciendo nuevas estrategias que se pueden incorporar, ya sea como complemento o cómo la forma de abordar esta didáctica, lo que dependerá de las decisiones que tome cada establecimiento. Indudablemente, no pretende ser la única ni la mejor forma de enseñar a la historia, pero aporta una visión creativa e innovadora, con sus tipos de entendimiento y herramientas cognitivas. Los educadores que entendemos cómo funcionan éstas, podemos entender cómo comprendemos y aprendemos y, por lo tanto, cómo enriquecer su didáctica, y no solo de la historia sino de cualquier tema. Lo central en esta teoría es que es coherente con la concepción de aprendizaje que plantea nuestro currículo nacional vigente, coloca al alumno en el centro del aprendizaje, no desvaloriza el conocimiento por sobre el desarrollo de habilidades, sino que reconoce y equilibra la importancia de ambos. No impone tampoco un currículo determinado, sino que apunta directamente a cómo pensar y diseñar la clase, por lo que, como ya se mencionara, es aplicable en cualquier contexto y en cualquier nivel de enseñanza.

Este artículo da una mirada general y breve a la teoría y los postulados de la Educación Imaginativa propuesta por Kieran Egan, pero espera provocar el interés por ella y que sea cada vez más un tema de análisis y reflexión para los educadores y en particular para sus formadores.

\section{Referencias bibliográficas}

\section{Fuentes primarias}

a) Entrevistas

Kieran Egan, Vancouver, Canadá, I-2015.

\section{Fuentes secundarias}

a) Artículos y capítulos de libros

Hallam, R. (1969). "Piaget and the teaching of history", en Educational Research. Vol. 12, № 1, pp. 3-12. 


\section{b) Libros}

Baquero, R. (2004). Vigotsky y el aprendizaje escolar. Buenos Aires.

Dewey, J. (1966). Democracy and Education: An Introduction to the Philosophy of Education. New York: Free Press.

Egan, K. (1986). Teaching as storytelling: An Alternative Approach to Teaching and Curriculum in the Elementary School. Chicago: University of Chicago Press.

Egan. K. (1996). The Educated Mind: How congnitive tools shape our understanding. Chicago: University of Chicago Press.

Egan, K. (2002). Getting it wrong from the beginning. Yale: Yale University Press.

Egan, K. (2005). An imaginative approach to teaching. New Jersey: John Wiley \& Sons.

Egan, K., M. Stout y K. Takaya (2007). Teaching and Learning Outside the Box: How to grab your students by their brains. Canada: Joseey-Bass.

Egan, K. (2008). Fantasía e Imaginación: su poder en la enseñanza. España: Morata.

Egan, K. (2010). Learning in Depth: A simple innovation that can transform schooling. Chicago: University of Chicago Press.

Egan, K y Judson, G. (2016). Imagination and the Engaged Learner: Cognitive Tools for the Classroom. New York.

Egan, K. (2018). Mentes Educadas, Santiago: Ediciones Universidad Finis Terrae.

Elkind, D. (1976). Child development and education: A Piagetian perspective. Oxford: Oxford University Press.

Judson, G. (2010). A New Approach to Ecological Education. New York.

Paley, V. G. (1981). Wally's stories. Cambridge, MA: Harvard University Press.

Paley, V. G. (1984). Boys and girls: Superheroes in the doll corner. Chicago: University of Chicago Press.

Paley, V. G. (1990). The boy who would be a helicopter: The uses of storytelling in the classroom. Cambridge, MA: Harvard University Press.

Robinson, K. (2017). Out of our minds: The power of being creative. United Kingdom: John Wiley \& Sons.

Vygotsky, L. S. (1978). Mind in Society. Cambridge, MA: Harvard University Press. 
Vedovelli, C. (2014). Neuro-teaching in Primary School. The principles of Feuerstein's mediated learning integrated into school curriculum. Italy: European Conference on Education, Brighton, University of Sassari.

\section{Cómo citar este artículo:}

Matte, M. de la L. (2018) "La Educación Imaginativa y la enseñanza de la historia", en Revista de Historia y Geografía, №39, pp. 143-161, Escuela de Educación en Historia y Geografía, Universidad Católica Silva Henríquez (UCSH), Santiago de Chile.

[http://ediciones.ucsh.cl/ojs/index.php/RHyG/article/view/1696/1558] 